\title{
Comparison of Effect of Metakaolin and silica Fume on Fly Ash Concrete Performance
}

\author{
HOU Yunfen ${ }^{1, \mathrm{a}}$, SI WuBao ${ }^{1, \mathrm{~b}}$, PENG XiaoDong ${ }^{1, \mathrm{c}}$ and XING Nan ${ }^{1, \mathrm{~d}}$ \\ ${ }^{1}$ Beijing High Institution Research Center for Engineering Structures and New Materials, Beijing \\ University of Civil Engineering and Architecture, Beijing, , 100044

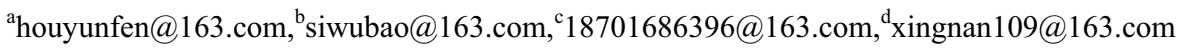

\begin{abstract}
Silica fume is a common mineral admixture used in HSC and HPC, but being its high price and shrinkage in concrete, its usage is under restrictions. As a new mineral admixture, metakaolin gets more and more attention. In order to compare the difference between silica fume and metakaolin, the effects of metakaolin and silica fume on concrete workability, compressive strength, and chloride penetration resistance are studied. It shows that incorporating with fly ash together, silica fume reduces the slump extension, but metakaolin can increases it; silica fume can increases early strength more than metakaolin can, but it isn't useful for later and long-time strength; metakaolin not only can increase early strength, but also can improve long-time strength. Silica fume and metakaolin can increase the chloride penetration resistance. As a new mineral additive, metakaolin can play a role in concrete which silica fume does, even much better than silica fume.
\end{abstract}

Keywords: metakaolin; silica fume; performance; mineral admixture

\section{Introduction}

Basing on "activity effect", "morphology effect" and "micro-aggregate effect", fly ash is widely used in concrete as a mineral admixture to improve workability and durability, but reduce strength, especial early strength ${ }^{[1]}$.

Silica fume is a highly active mineral admixture with high specific surface areas. By "filling effect" and "pozzolanic effect", silica fume can improve the pore structure and interface structure to improve compactness of concrete, and then increase concrete strength and durability ${ }^{[2 \sim 4]}$.

\section{Raw Materials and Method}

\subsection{Raw Materials.}

The chemical compositions of metakaolin and silica fume are listed in Table 1. Metakaolin's specific surface area and average grain sizes are $2.75 \mathrm{~m}^{2} / \mathrm{g}$ and $2.18 \mu \mathrm{m}$ respectively, and its particle morphology is shown in Fig.1 which shows that metakaolin is 
irregular flaky and loose porous particles. The specific surface area and average grain sizes of silica fume are $8.56 \mathrm{~m}^{2} / \mathrm{g}$ and $0.27 \mu \mathrm{m}$ respectively, and its particle morphology is shown in Fig. 1 which shows that silica fume is very small spherical particles.

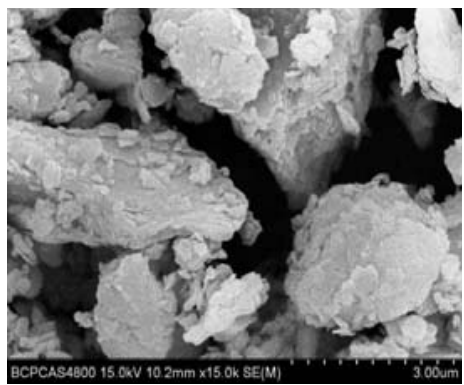

(a) Metakzolin

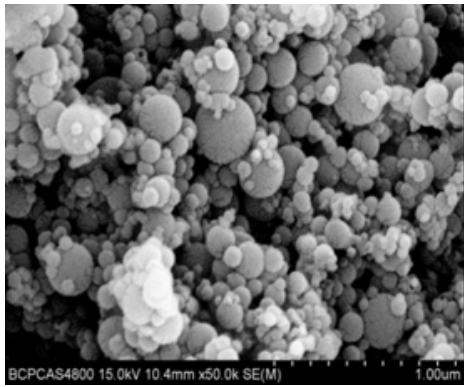

(b) silica fume

Fig. 1 The morphology of metakaolin and silica fume

The grade II fly ash is used. P.O 42.5 made in Jinyu factory is used. The water-reducing rate of polycarboxylate superplasticizer is $35 \%$.

The nominal fraction of coarse aggregate is $5 \sim 25 \mathrm{~mm}$, whose voidage is $42 \%$. The fine aggregate is manufactured sand whose fineness module is 2.7 , and the particle graduation belongs to II area.

\subsection{Method.}

The tests of workability, strength and durability are based on GB50080, GB50081 and GB50082.

\subsection{Result and Analyze.}

Basing on the ratio of pure cement concrete (code is C), the dosage of fly ash is $35 \%$ to replace cement for fly ash concrete (code is FA), and besides $35 \%$ fly ash, dosage of metakaolin (code is $\mathrm{MK}$ ) or silica fume is $8 \%$ to replace cement for metakaolin concrete (code is MK) or silica fume concrete (code is SF). In order to compare the effect degree of fly ash and metakaolin and silica fume, the amounts of other raw materials are same, and because silica fume is always used in high strength concrete, the ratio of water to bind is 0.29 ; ratios of four type concrete are listed in Table 1 .

Table 1 Ratios of Four Types Concretes $\left(\mathrm{Kg} / \mathrm{M}^{3}\right)$

\begin{tabular}{ccccccccc}
\hline code & $\begin{array}{c}\text { Ceme } \\
\text { nt } \\
(\mathrm{C})\end{array}$ & $\begin{array}{c}\text { Fly } \\
\text { ash } \\
(\mathrm{FA})\end{array}$ & $\begin{array}{c}\text { Silica } \\
\text { fume } \\
(\mathrm{SF})\end{array}$ & $\begin{array}{c}\text { Metakao } \\
\text { lin (MK) }\end{array}$ & $\begin{array}{c}\text { Fine } \\
\text { aggreg } \\
\text { ate }\end{array}$ & $\begin{array}{c}\text { Coarse } \\
\text { aggreg } \\
\text { ate }\end{array}$ & $\begin{array}{c}\text { Wat } \\
\text { er }\end{array}$ & $\begin{array}{c}\text { Water-reduc } \\
\text { ing agent }\end{array}$ \\
\hline C & 580 & 0 & 0 & 0 & 747 & 992 & 170 & 6.23 \\
FA & 377 & 203 & 0 & 0 & 747 & 992 & 170 & 6.23 \\
SF & 377 & 157 & 46 & 0 & 747 & 992 & 170 & 6.23 \\
MK & 377 & 157 & 0 & 46 & 747 & 992 & 170 & 6.23 \\
\hline
\end{tabular}




\subsection{Effect of Metakaolin and silica Fume on Concrete Workability.}

The slump and slump extension results of four type concretes are listed in Table 2 .

Table 2 The Slump And Slump Extension Results (Mm)

\begin{tabular}{ccc}
\hline code & slump & slump extension \\
\hline C & 220 & 480 \\
FA & 230 & 640 \\
SF & 240 & 360 \\
MK & 230 & 600 \\
\hline
\end{tabular}

The slump only can reflect the yield stress, but cannot reflect the viscosity of concrete mixture, so it can reflect the fluidity of plastic concrete mixture, but for high flow concrete mixture, when slump is bigger than some critical value, it cannot reflect the fluidity. For example, the slump is very big, but the mixture shows circular table shape, even is projecting on middle part, which means that the mixture is too thick to pump and cannot fill the space between rebar. The slump extension can not only reflect the yield stress, but also viscosity, and does not have some circular value. For high flow concrete, the slump extension is used to reflect the fluidity.

It can be seen from Table 2 that the slumps of four type concretes are similar, about $230 \mathrm{~mm}$, whether adding fly ash and metakaolin or silica fume, which shows that slump cannot reflect the effect of metakaolin and silica fume on the fluidity. Table 2 shows that the slump extensions of these concretes are very different, the slump extension of sample $\mathrm{C}$ $480 \mathrm{~mm}$, and then adding $35 \%$ fly ash to replace cement (that is sample F), the slump extension increases to $640 \mathrm{~mm}$, furthermore, adding $8 \%$ silica fume to replace cement more (that is sample SF), the slump extension drops to $360 \mathrm{~mm}$, but if adding $8 \%$ metakaolin to replace cement (that is sample MK), the slump extension is $600 \mathrm{~mm}$ which is greater than that of sample SF and similar to that of sample F. The slump extension can better reflect the different effect of different admixtures on fluidity of high flow concrete. With the "grain effect", fly ash replacing cement by $35 \%$ can increases the fluidity from $480 \mathrm{~mm}$ upper to $640 \mathrm{~mm}$. When adding silica fume by $8 \%$, great fineness makes concrete mixture become more thickness, so that slump extension drops to $360 \mathrm{~mm}$. Comparing with silica fume, effect of metakaolin on fluidity is ignore.

\subsection{Effect of Metakaolin and silica Fume on Concrete Strength.}

The compressive strengths of four type concretes are listed in Fig. 2 


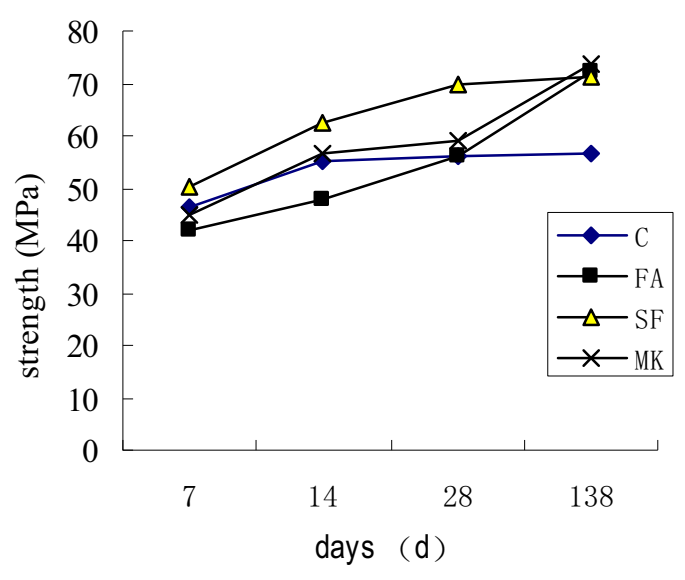

Fig. 2 the compressive strengths of four type concretes

Fig. 2 shows that strength of sample $\mathrm{C}$ increases mainly in early days, strength does not increase after 14 days and strength is smallest among four type concretes after 138days. For sample F, early strength is smallest, but strength increase much quickly up to $72 \mathrm{MPa}$ after 138 days, which is 1.3 times to sample C. Adding metakaolin and silica fume can increase early strengths of fly ash concrete, especial silica fume can. Comparing with silica fume, metakaolin can increase long-time strength much more up to $73 \mathrm{MPa}$.

In sum, mixing with fly ash, silica fume can increase early strength by a large margin, but the increasing effect of silica fume on long-time strength is ignore, even makes long-time strength be inferior to that of fly ash concrete. Metakaolin not only increases early strength, but also long-time strength of fly ash concrete ${ }^{[5 \sim 8]}$.

When silica fume is added in concrete, much more active $\mathrm{SiO}_{2}$ (see Table 1) react with $\mathrm{Ca}(\mathrm{OH})_{2}$ to produce $\mathrm{C}-\mathrm{S}-\mathrm{H}$, which is called twice hydration reaction. Because of great fineness, silicate fume can react much quickly, and then so many tiny particles of silica fume also can fill the space between cement particles to make concrete much denser ${ }^{[9 \sim 10]}$. Both the chemical active function and physical filling functions act together to increase the strength of concrete, especial early strength. As for as concerned metakaolin, except for physical filling function, particle is coarser than that of silica fume, so the speed of twice hydration reaction is slower, the early strength is less, but besides active $\mathrm{SiO}_{2}$, there is much active $\mathrm{Al}_{2} \mathrm{O}_{3}$ (see Table 1) which can react with $\mathrm{Ca}(\mathrm{OH})_{2}$ to hydrated calcium aluminate, then react with gypsum to produce Aft which is very useful to improve strength, that is reason why metakaolin can increase long-time strength of fly ash concrete ${ }^{[11 \sim 13]}$.

\subsection{Effect of metakaolin and silica fume on chloride penetration resistance of concrete.}

After standard curing for 28 days, the diffusion coefficient of chloride ion is measured, the results are listed in Table 3. 
Table 3 Diffusion Coefficient Of Chloride Ion Of Four Type Concretes

\begin{tabular}{llllll}
\hline code & C & F & MK & SF \\
\hline
\end{tabular}

Diffusion coefficient of chloride ion $\left(10^{-8} \mathrm{~cm}^{2} / \mathrm{s}\right) \quad 9.41 \quad 7.66 \quad 7.47 \quad 3.20$

Table 3 indicates that comparing to sample $\mathrm{C}$, admixtures can reduce diffusion coefficient of chloride ion of concretes, especial for sample SF, the diffusion coefficient of chloride ion reduces to 3.20 , which means that silica fume can improve the compactness of concrete during 28 days, and this result conforms to the result of 28 days strength.

The diffusion coefficient of chloride ion is mainly affected by pore structure and hydration products of concrete ${ }^{[14]}$, which decide the diffusion resistance for chloride penetration and solidification ability which includes physical solidification and chemical solidification. Basing on the physical filling function and chemical reaction function, mineral admixture such as fly ash, metakaolin and silica fume can improve the microstructure by reducing porosity, refining pore size, and optimizing interface structure, which can increase the diffusion resistance and block the permeation passage of chloride ions $^{[15 \sim 17]}$. Twice hydration reaction can produce more C-S-H and Aft. Basing on its high specific surface areas, C-S-H can solidify chloride ions by physical absorption, and Aft can react with chloride ions to form calcium chloroaluminate hydrate to solidify chloride ions, which is called chemical solidification ${ }^{[18 \sim 19]}$.

Because of great fineness which can improve microstructure and rapid reaction speed which can produce more C-S-H, silica fume can solidify much more chloride ions to reduce the diffusion coefficient of chloride ion.

\section{Conclusions}

The slump cannot reflect the fluidity of high flow concrete, but slump extension can reflect the fluidity of high flow concrete. Fly ash can notably increase the slump extension, but mixed with silica fume, the slump extension is reduced markedly. The effect of metakaolin on slump extension of fly ash concrete is neglectful. Silica fume can increase the early strength, cannot affect the long-time strength. The increasing degree of early strength by metakaolin is less then that by silica fume, but metakaolin can increase long-time strength, which even exceeds that of silica fume concrete. Silica fume and metakaolin can improve the chloride penetration resistance of fly ash concrete after standard curing 28 days, especial for silica fume.

In sum, as a new mineral admixture, metakaolin not only can increase slump extension, but also can increase early and long-time strength; it is benefit of the chloride penetration resistance, too.

\section{References}

1. LU Qiuyan,Development and Application Prospect of Metakaolin in China,express information of mining industry , 2004, 20(7): 7 10

2. SUN XiaoWei,LI WenXue,SUN Wei,Analyse Metakaolin is in the application of the concrete. Science \& Technology Information,2010, (9): 769, 752 
3. HUANG Zhan,XING Feng,XING Yuanyuan, Research on concrete performance improvements that mixed with Metakaolin and Slag. Concrete,2008, (4): 51 53, 59

4. R, Hs W. Strength estimation model for high-strength concrete incorporating metakaolin and silica fume. Cement and Concrete Research, 2005, 35(4): 688 695

5. CAO YingJi,the research progress of Metakaolin as high performance concrete admixture,Guangdong Building Materials,2006,(4): 11 14

6. CAO ZhengLiang,LI Weiwen,CHEN YuLUN,the application of Metakaolin in concrete, Shenzhen University Journal,2004, 21(2): 183 186

7. Asbridge A H, Chadbournb G A, Page C L. Effects of metakaolin and the interfacial transition zone on the diffusion of chloride ions through cement mortars. Cement and Concrete Research, 2001, 31: 1567 1572

8. Brooks J J, Johari M A M. Effect of metakaolin on creep and shrinkage of concrete. Cement \& Concrete Composites, 2001, 23: 495 502

9. Khatib J M, Clay R M. Absorption characteristics of metakaolin concrete. Cement and Concrete Research, 2003: 1 11

10. Al-Akhras N M. Durability of metakaolin concrete to sulfate attack. Cement and Concrete Research, 2006, 36: 1727 1734

11. Arikan M, Sobolev K, Ertun T. Properties of blended cements with thermally activated kaolin. Construction And Building Materials, 2009, 23: 62 70

12. Al-Akhras N M. Durability of metakaolin concrete to sulfate attack. Cement and Concrete Research, 2006, 36: 1727 1734

13. Courard L, Darimont A, Schouterden M, et al. Durability of mortars modified with metakaolin. Cement and Concrete Research, 2003, 33: 1473 1479

14. LI Xin,XING Feng,CANG Feiyu,Research on chlorine ion permeability and charges passed in metakaolin blended cement concrete,Concrete,2003, (11): 36 38

15. Khatib J, Wild S. Pore size distribution of metakaolin paste. Cement and Concrete Research, 1996, 26: 1545 1553

16. Kostuch J A, Walters V, Jones T R. High performance concretes in-corporating metakaolin: A review: R.K. Dhir, M.R. Jones (Eds.), Concrete 2000. E\&FN Spon, London, UK: 19931799 1811

17. Bai J, Wild. S. Investigation of the temperature change and heat evolution of mortar incorporating PFA and metakaolin. Cement \& Concrete Composites, 2002, 24(02): $201 \sim 209$

18. WANG Baomin,LIU Wei,Research on chlorine ion permeability in metakaolin blended cement concrete,Journal of Disaster Prevention and Mitigation Engineering,2010, 30(z1): 369 372

19. LI Xin,XING Feng,CANG Feiyu,Investigation on Reducing Chlorine Ion Charges Passed in Concrete by Blending Metakaolin and Its Ternary Blends,Journal of Materials Science\&Engineering,2004, 22(6): 809 812. 